\title{
LEUKOCYTOCLASTIC VASCULITIS AFTER COVID-19 VACCINATION- CASE REPORT
}

\author{
Luana Gerheim Machado ${ }^{1, \star}$, Camila dos Reis Neves, Ana Elisa Silveira de Gouvêa e Lopes ${ }^{1}$, Bruno Fiorilo Grillo1 ${ }^{1}$, Yasmin Zaka \\ Tostes $^{1}$, Gabriela dos Santos Lopes ${ }^{2}$, Herval de Lacerda Bonfante ${ }^{1}$, Heloina Lamha Machado Bonfante ${ }^{1}$
}

1.Faculdade de Ciências Médicas e da Saúde de Juiz de Fora, Juiz de Fora (MG), Brazil; 2.Hospital Maternidade Therezinha de Jesus, Juiz de Fora (MG), Brazil.

*Corresponding author: luanagerheim@yahoo.com.br

\section{BACKGROUND}

According to a statement by Global Advisory Committee's WHO for Vaccine Safety, the most reported reactions of Oxford/ AstraZeneca vaccine against COVID-19 (AZD1222) are mild and self-limited, with reports of very rare side effects (>1/10,000 and $<1 / 1,000)$. In this context, the objective of the study is to report a rare case of leukocytoclastic vasculitis after SARS-CoV-2 vaccination. This pathology consists in an inflammation of small vessels, mainly venules, by the deposition of immune complexes.

\section{CASE REPORT}

On April 27, 2021, a 62-year-old female patient without comorbidities, received the first dose of Oxford/AstraZeneca COVID-19 vaccine (AZD1222). Within 6 days, she developed chills, bilateral knee arthralgia concomitant with pain and ankle swelling, in addition to a burning sensation in the lower limbs and presence of palpable purpuric papules which extended to the proximal region of thighs and increased progressively. The biopsy of an irregular skin fragment from the right leg showed extravasation of red cells in the upper dermis, perivascular and superficial lymphocytic inflammatory infiltrate, and absence of malignancy in the cut planes examined. Laboratory tests showed leukocytosis $(11.740 / \mathrm{mm} 3)$ with left shift, elevated quantitative C-reactive protein $(5.36 \mathrm{mg} / \mathrm{dL})$ and high fibrinogen levels ( $432 \mathrm{mg} / \mathrm{dL}$ ). The patient was promptly treated with prednisone $40 \mathrm{mg} /$ day for 10 days with progressive tapering of the medication and fexofenadine hydrochloride $180 \mathrm{mg} /$ day for 5 days. There was a good clinical evolution of the condition and after 10 days the patient had no more symptoms. There were no sequelae. Patient has not yet received the second dose.

\section{CONCLUSION}

This case has a great scientific value as it is essential for post-approval pharmacovigilance of the Oxford/AstraZeneca vaccine against COVID-19 (AZD1222) and serves as a basis for physicians to evaluate future patients with suspected leukocytoclastic vasculitis associated with COVID-19 vaccine. It should be noted that these rare adverse events associated with vaccination are of important knowledge but should not impact the great utility of vaccination and the well-documented safety profile of available vaccines.

\section{KEYWORDS}

Leukocytoclastic vasculitis, COVID-19 vaccine, Adverse events. 